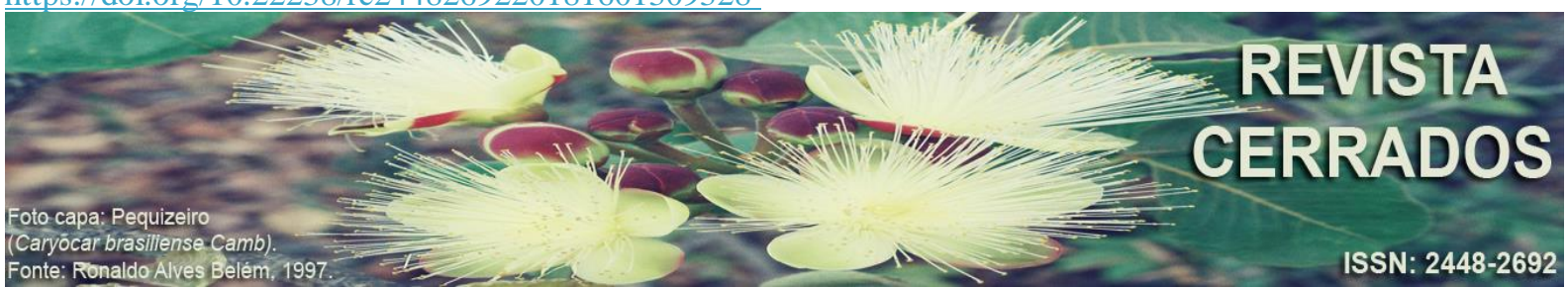

\title{
DIÁSPORA INDÍGENA NO LESTE BRASILEIRO: a resistência e o protagonismo dos povos indígenas nos "sertões" de Minas Gerais ${ }^{1}$
}

\section{INDIGENOUS DIASPORA IN THE BRAZILIAN EASTE: the resistance and the protagonism of the indigenous peoples in the "sertões" of Minas Gerais}

\section{DIÁSPORA INDÍGENA EN EL ESTE BRASILEÑO: la resistencia y el protagonismo de los pueblos indígenas en los "sertões" de Minas Gerais}

\author{
Ludimila de Miranda Rodrigues Silva \\ Universidade Federal de Minas Gerais - UFMG \\ E-mail: <ludimilarodrigues86@gmail.com>.
}

\begin{abstract}
RESUMO
Desde a colonização do território brasileiro, os povos indígenas vêm passando por processos de diáspora que desconsideram toda a história cultural e social em seus territórios tradicionais. Tais perspectivas são ainda mais evidenciadas em regiões fora da Amazônia, como no leste brasileiro, onde atualmente existem poucas aldeias indígenas. Nesse sentido, este artigo tem por objetivo analisar a diáspora indígena no leste brasileiro e a sua emergência política e identitária, ainda tão pouco reconhecida e valorizada pela sociedade que, muitas vezes, ainda desconhece a presença de diversas aldeias indígenas no sudeste brasileiro. Para tal foram realizadas entrevistas com algumas dessas populações nos Vales do Jequitinhonha e Mucuri, além de levantamento de dados bibliográficos, cartográficos e documentais regionais e de entidades não governamentais que apoiam tais populações. Nesse sentido, ressaltamos que dialogar sobre o passado, presente e futuro desses povos faz-se cada vez mais necessário no contexto atual, uma vez que, muitos de seus direitos adquiridos nos últimos anos vêm sendo ameaçados por uma série de políticas públicas e posicionamentos estigmatizantes e desconstrutivos da luta e resistência indígena.
\end{abstract}

Palavras Chave: Povos Indígenas. Leste Brasileiro. "Sertões” de Minas Gerais.

\section{ABSTRACT}

Since the colonization of Brazilian territory, indigenous peoples have been going through diasporic processes that disregard all cultural and social history in their traditional territories.

\footnotetext{
${ }^{1}$ Trabalho apresentado no V Colóquio Cidade e Região (UNIMONTES), selecionado para publicação nesta edição da Revista Cerrados.
} 
SILVA, L. M. R.

Diáspora indígena no leste brasileiro: a resistência e o protagonismo dos povos indígenas nos "sertões" de Minas Gerais

Such perspectives are even more evident in regions outside the Amazon, such as in eastern Brazil, where there are few indigenous villages. In this sense, this article aims to analyze the indigenous diaspora in the Brazilian east and its political and identity emergence, still so little recognized and valued by society that, many times, is still unaware of the presence of several indigenous villages in southeastern Brazil. For this purpose, interviews with some of these populations were carried out in the Jequitinhonha and Mucuri Valleys, as well as the collection of regional bibliographical, cartographic and documentary data and nongovernmental entities that support these populations. In this sense, we emphasize that dialogue about the past, present and future of these peoples is becoming increasingly necessary in the current context, since many of their rights acquired in recent years are being threatened by a series of public policies and stigmatizing positions and deconstructive of indigenous struggle and resistance.

Keywords: Indigenous Peoples. Brazilian East. “Sertões” of Minas Gerais.

\section{RESUMEN}

Desde la colonización del territorio brasileño, los pueblos indígenas vienen pasando por procesos de diáspora que desconsideran toda la historia cultural y social en sus territorios tradicionales. Tales perspectivas son aún más evidenciadas en regiones fuera de la Amazonia, como en el este brasileño, donde actualmente existen pocas aldeas indígenas. En este sentido, este artículo tiene por objetivo analizar la diáspora indígena en el este brasileño y su emergencia política e identitaria, aún tan poco reconocida y valorada por la sociedad que, muchas veces, todavía desconoce la presencia de diversas aldeas indígenas en el sudeste brasileño. Para ello se realizaron entrevistas con algunas de esas poblaciones en los Valles del Jequitinhonha y Mucuri, además de levantamiento de datos bibliográficos, cartográficos y documentales regionales y de entidades no gubernamentales que apoyan a dichas poblaciones. En este sentido, resaltamos que dialogar sobre el pasado, presente y futuro de esos pueblos se hace cada vez más necesario en el contexto actual, ya que muchos de sus derechos adquiridos en los últimos años vienen siendo amenazados por una serie de políticas públicas y posicionamientos estigmatizantes y desconstructivos de la lucha y resistencia indígena.

Palabras Clave: Pueblos Indígenas. Este Brasileño. "Sertões” de Minas Gerais.

\section{INTRODUÇÃO}

Os povos indígenas brasileiros, desde a colonização de seus territórios e, inclusive, até os dias atuais, vêm passando por uma série de contextos diaspóricos que explicitam não apenas a sua atual configuração socioespacial vinculadas, muitas vezes, à luta por delimitação e manutenção de seus territórios, como também às próprias dinâmicas sociais, culturais, políticas e ambientais desses grupos. Muitos desses contextos, todavia, foram invisibilizados e marginalizados até o século passado, emergindo atualmente, nesse sentido, 
SILVA, L. M. R.

Diáspora indígena no leste brasileiro: a resistência e o protagonismo dos povos indígenas nos "sertões" de Minas Gerais

por meio da presença e autonomia política e social que estes povos têm desenvolvido junto à sociedade dominante. A presença indígena nos gabinetes políticos, nos órgãos governamentais, escolas, universidades e, principalmente, na resistência diária de seus territórios têm propiciado ainda a revelação de muitas dessas vivências da diáspora indígena preservadas na memória e na oralidade dessas populações. Nesse sentido, este artigo tem por objetivo analisar alguns destes contextos de diáspora indígena no recorte regional do leste brasileiro, além do protagonismo e emergência política e identitária desses povos, ainda tão pouco reconhecidos e valorizados pela sociedade que, inclusive, desconhece a presença de diversas aldeias indígenas no sudeste brasileiro.

Para tal foram realizadas pesquisas em arquivos históricos estaduais e municipais em busca de bibliografias locais e regionais que retratassem essas realidades no recorte regional do leste brasileiro (norte do Espírito Santo, sudeste da Bahia e nordeste e leste de Minas Gerais) - principalmente nas mesorregiões de Jequitinhonha e Vale do Rio Doce, onde estamos desenvolvendo pesquisas desde 2008 no âmbito do Grupo de Pesquisa CNPq Terra \& Sociedade da Universidade Federal de Minas Gerais. Além disso, a pesquisa documental considerou ainda a análise de uma série de bibliografias clássicas sobre a questão indígena brasileira, tais como: Melatti (2009), Ribeiro (1983), Gallais (2002), Marcato (1979) e Moreno (2011) que retratam os processos migratórios, etnolinguísticos e da luta e resistência dos povos indígenas brasileiros. Em projetos de pesquisa realizados entre $2010-2011^{2}$ e $2014-$ $2015^{3}$, financiados pela FAPEMIG, foram realizadas entrevistas em comunidades indígenas desse recorte regional como: Krenak (município de Resplendor-MG); Pataxó (CarmésiaMG); Pankararú - Pataxó (Aldeia Cinta-Vermelha em Araçuaí-MG), além de contatos realizados também por meio de encontros regionais, científicos e até de formação de professores indígenas que acontecem semestralmente no âmbito da universidade. Outra metodologia utilizada nessa pesquisa foi a consulta a fontes secundárias de organizações não governamentais (ONGs) que atuam nesses territórios como: o Instituto Socioambiental (ISA) e a Associação Nacional de Ação Indígena (ANAI) para entender a dinâmica de ações e projetos que vem sendo desenvolvidos nesse emblemático território.

\footnotetext{
${ }^{2}$ Etnogeografia, etnossustentabilidade e a organização e gestão do território de comunidades tradicionais e indígenas no Estado de Minas Gerais.

3 Etnogeografia, paisagens culturais e gestão do território em comunidades tradicionais do Vale do Jequitinhonha/MG.
} 
SILVA, L. M. R.

Diáspora indígena no leste brasileiro: a resistência e o protagonismo dos povos indígenas nos "sertões" de Minas Gerais

Posto isso, esse trabalho busca contribuir com o resgate e o reconhecimento da luta e resistência das populações indígenas na manutenção de seus territórios tradicionais, de sua herança cultural num recorte geográfico ainda pouco visibilizado pela sociedade e pelos órgãos e entidades públicas. Dessa forma, este artigo encontra-se divido em três partes: na primeira realizamos uma análise sobre os processos de diáspora dos povos indígenas no leste brasileiro (principalmente norte do Espírito Santo e sul da Bahia), destacando desde os processos históricos de exclusão à emergência sociopolítica dos mesmos no âmbito de projetos socioambientais atuais desenvolvidos em seus territórios; com enfoque maior nas comunidades de Minas Gerais, realizamos na segunda parte uma análise dos processos de etnocídio pelos quais os Borun e algumas outras etnias do leste mineiro sofreram no âmbito da ocupação do território mineiro e por fim, na terceira parte, apresentamos um levantamento da situação fundiária dos povos indígenas em Minas Gerais, destacando ainda os principais projetos e perspectivas dos mesmos no contexto atual.

\section{Diáspora dos povos indígenas do leste brasileiro}

A região geográfica do leste brasileiro, correspondente ao norte do Espírito Santo, sudeste da Bahia e nordeste de Minas Gerais, permaneceu, de certa forma, até o final do século XVII, indevassada pelos colonizadores, os quais apesar de já terem estabelecido contatos e uma série de incursões nos territórios indígenas nas capitanias de Ilhéus, Porto Seguro e Espírito Santo, nesses "sertões do leste" encontraram forte resistência contra seu ingresso e estabelecimento em territórios originalmente indígenas.

Nas regiões litorâneas, o primeiro contato, ainda amistoso, se deu, sobretudo, com povos tupis, como os Tupinambá, Tupinikim, Temiminó e Potiguara, em busca de pau-brasil. E foi com a implantação das capitanias hereditárias que se estabeleceram as guerras de conquista, contra as quais a reação indígena, já no século XVI, foi intensa. Com o escravismo e os aldeamentos jesuíticos associados aos engenhos de cana-de-açúcar, que demandavam abundantemente mão-de-obra, os conflitos se disseminaram ainda mais pelas áreas costeiras. Os Goitaká(ses) ou Goitá, no atual estado do Rio de Janeiro, não aceitavam a presença dos europeus, assim como os Tupinambá, na capitania da Bahia, os Tupinikim de Ilhéus, dentre outros povos indígenas do leste (PREZIA, 2004). 
SILVA, L. M. R.

Diáspora indígena no leste brasileiro: a resistência e o protagonismo dos povos indígenas nos "sertões" de Minas Gerais

Com o Ciclo do Ouro, no século XVII, os indígenas passam a ser levados de suas regiões de origem para trabalhar nas minas e fazendas de São Paulo e Minas Gerais. Enquanto as etnias da região de São Paulo foram utilizadas como "carregadores de tropas das bandeiras", os de Minas "foram requisitados como guias e suas aldeias se tornaram locais de pousos e abastecimento de comida" (PREZIA, 2004, p.37). Concomitantemente à mineração iniciou-se ainda a fase da pecuária frente à demanda de abastecimento de carne nas vilas que se formavam em torno dos garimpos, período que correspondeu à ocupação do médio e alto São Francisco, Recôncavo Baiano e centro do Espírito Santo (MELATTI, 2009).

A abertura de novos caminhos e desmonte dos aldeamentos missionários no século XVIII e início do XIX configurou, por sua vez, um cenário de abandono e guerra aos grupos que cruzassem "o caminho do desenvolvimento", o que se concretizou com a carta régia de 1808 (que decretou "guerra justa" aos indígenas dos sertões mineiros) e com o estabelecimento de quartéis em todo o leste brasileiro. Nesse sentido, no início do século XIX foram implantados 35 quartéis no sul da Bahia e leste/nordeste de Minas; e 38 no Espírito Santo. Muitos confrontos e extermínios se estenderam então por toda a costa leste, sendo concluída a ligação entre Rio de Janeiro e Salvador pelo litoral no século XX, quando grande número de aldeias das etnias Borun, Pataxó, Tupinikim, dentre outras, já se encontravam exterminadas ou transformadas em vilas, como o já mencionado aldeamento de Itambacuri, no norte de Minas Gerais (PREZIA, 2004).

Dentre os "bolsões indígenas" que ainda restavam no leste brasileiro em meados do século XIX, entre a região do sul da Bahia e o vale do rio Doce ao longo da vertente oriental da serra do Mar, destacavam-se os últimos refúgios dos índios Kamakã, Pataxó, Maxakali, Puri-Coroado e os grupos de Botocudos. De acordo com Ribeiro (1995), esses grupos não tinham a agricultura como prática de subsistência, sobrevivendo a partir da caça e da coleta nas matas ciliares dos principais rios da região como o Pardo, o das Contas, o Jequitinhonha, o Mucuri, o São Mateus e o Doce.

Os povos indígenas aí domiciliados receberam então designações imprecisas e genéricas, originárias do processo de "tupinização", como, por exemplo: Aimorés (temidos desde o século XVI, por aterrorizar a todos que adentrassem o seu território); Botocudos ("porque alguns grupos usavam grandes botoques nos lóbulos das orelhas e no lábio inferior"); Coroados ("por rasparem a cabeleira em círculo, três dedos acima das orelhas, 
SILVA, L. M. R.

Diáspora indígena no leste brasileiro: a resistência e o protagonismo dos povos indígenas nos "sertões" de Minas Gerais

formando uma espécie de coroa"); e ainda Tapuia, vocábulo, como já se mencionou anteriormente, originário das relações inóspitas entre os índios da costa (tupi) e os do sertão, que não compartilhavam com os primeiros a mesma língua e cultura.

No sudeste da Bahia, além das "vilas de índios", encontravam-se, predominantemente, índios das etnias Pataxó e Maxakali, e também muitos luso-brasileiros e imigrantes, além de alguns grupos autônomos que viviam nos resquícios de Mata Atlântica nas bacias dos rios Gongoji, Cachoeira, Pardo e Jequitinhonha. Todavia, grande parte desses grupos fora dizimada pelas frentes de expansão da lavoura de cacau entre 1910 e 1930, restando apenas dois pequenos grupos das etnias acima mencionadas (SAMPAIO, 2010). Na Bahia, em 1926 foram criados os postos indígenas para alocar os índios do sul do estado, como os Pataxó Hã-hã-hãe, Borun e Baenã no Posto Caramuru; e os Cariris-sapuiás, Camacãs e outros tupis, de antigos aldeamentos invadidos, no Posto Indígena Paraguaçu. Embora, tais terras tenham sido oficialmente demarcadas entre 1936 e 1937, com o destaca Sampaio (2010, p.2) a reserva indígena Caramuru-Paraguaçu foi "imediatamente invadida por fazendeiros de cacau e gado, que se valeram de arrendamentos e da corrupção de servidores do Serviço de Proteção aos Índios (SPI) para desencadear um novo processo de expulsão dos índios que perdurou [...] até a década de 1970".

Ainda resistentes às pressões dos fazendeiros, um significativo grupo da etnia Pataxó (e alguns Maxakali) residiam no extremo sul do baiano, na foz do rio Corumbau, reunidos na aldeia de Barra Velha. Na década de 1940 são atingidos por uma iniciativa estatal de criação do parque Monte Pascoal (a oeste da aldeia) para preservação do monumento natural e histórico da "Costa do Descobrimento". Em decorrência, mais uma vez do conflito institucional de políticas governamentais entre Fundação Nacional do Índio (FUNAI) e Instituto Brasileiro de Desenvolvimento Florestal (IBDF), os índios, ameaçados de perderem suas terras, foram em busca de soluções no Rio de Janeiro, e ao retornarem, sem respostas positivas, iniciaram uma forte resistência à implementação do parque, contida pelo "Fogo de 51". Ainda presente na memória dos Pataxó, o "Fogo de 51" foi uma emboscada aos índios, que foram levados à cidade, onde segundo "falsos informantes" eles estariam liberados para pegar mantimentos nos armazéns. Em resposta, a polícia invadiu a aldeia indígena, incendiando as casas, assassinando, espancando e até estuprando as mulheres sobreviventes. Diante tal situação, muitos índios Pataxó fugiram da aldeia ou foram levados 
SILVA, L. M. R.

Diáspora indígena no leste brasileiro: a resistência e o protagonismo dos povos indígenas nos "sertões" de Minas Gerais

para a Fazenda Guarani, em Carmésia/MG, movimento que se fortaleceu ainda mais após a consolidação do Parque Nacional Monte Pascoal, em 1961, quando os que ainda residiam no território, foram impedidos de plantar, privando-se assim o grupo do seu principal meio de sobrevivência. Apenas em 1971 a FUNAI retoma o Posto Indígena em Barra Velha (SAMPAIO, 2000).

Atualmente existem 12 Terras Indígenas - TI(s) no sudeste da Bahia, compreendendo um contingente populacional de aproximadamente 22.039 indígenas das etnias Pataxó, Pataxó Hã-há-hãe e Tupinambá distribuídos em aproximadamente 169.589 ha, que variam de 304 a 44.121 hectares. Sendo cinco terras indígenas regularizadas (ou homologadas); três declaradas (ou reservadas); três delimitadas (ou identificadas e aprovadas) e uma em estudo (ou identificação). Já no Espírito Santo, onde o processo de ocupação muito se aproxima ao sudeste baiano, atualmente existem três terras indígenas regularizadas/homologadas, com 3.033 índios em 18.221 ha, todas localizadas no município de Aracruz. A Terra Indígena Tupiniquim originou-se da junção entre as TI(s) Caieiras Velha e Pau Brasil, entre as quais havia um terreno sob a posse da Aracruz Celulose, que foi repassada aos índios depois de muitas lutas e audiências públicas em 2007.

Segundo o Instituto Socioambiental (2003) grande parte das terras indígenas passa por mais de um processo de homologação de terras, seja por conflitos com as áreas de entorno, ou por demandas internas das comunidades, como, por exemplo, as terras indígenas de Barra Velha do Monte Pascoal (aprovada com possível revisão) e Caramuru/Paraguassu (reservada e em processo de demarcação). Diante da importância histórica e econômica dessas áreas e dos conflitos de interesses relacionados a elas, a revisão ou demarcação de terras, em andamento, são conquistas inerentes à luta desses povos. Contudo, o seu reconhecimento frente à sociedade dominante ainda encontra obstáculos devido a notícias preconceituosas veiculadas na imprensa como: "Famílias Indígenas Ocupam Fazendas", "Indígenas Pataxó Bloqueiam BR-101”, “Índios Querem Mais Terrenos", "Demarcação assusta hoteleiros", dentre outras (são cerca de mais de 400 notícias que não expressam a situação pela visão do índio) (ISA, 2013).

Outra tendência que se observa, não apenas dentre os povos indígenas do leste, mas no contexto brasileiro como um todo, é o incremento populacional verificado nas últimas décadas, processo relacionado às conquistas jurídicas e territoriais, deslocamento de grupos 
SILVA, L. M. R.

Diáspora indígena no leste brasileiro: a resistência e o protagonismo dos povos indígenas nos "sertões" de Minas Gerais

entre áreas já demarcadas, junção de territórios indígenas e emergência de etnias que mantinham sua identidade escondida sob o disfarce de caboclos.

Um fenômeno associado às perspectivas de presente e futuro dessas populações, visando a sua manutenção nos territórios conquistados, é realização de projetos nas terras indígenas através de parcerias com organismos e empresas estatais, por exemplo, verifica-se que dos 15 projetos iniciados, entre 2008 e 2011, nas TI elencadas acima, três têm enfoque em "Cidadania e Representação Política" (de contrapartidas e implementação de atividades em projetos produtivos nas aldeias); quatro de "Geração de Renda" (práticas de desenvolvimento sustentável, mulheres indígenas artesãs); quatro de "Território" (agroecologia, gestão territorial, lavoura frutífera e piscicultura); dois de "Ambiente" (produção de alimentos e proteção ambiental/ manejo sustentável de pescado); um de "Educação Escolar" (biblioteca indígena) um de "Cultura" (museu virtual).

A presença desses projetos nas aldeias indica a articulação e afirmação política, territorial, sociocultural e econômica das populações indígenas, que cada vez mais têm buscado novas alternativas de subsistência nos atuais contextos ambientais (muitas vezes desmatados e já marcados pelo uso insustentável de fazendeiros ou grandes empresas) associando ao conhecimento tradicional as práticas auto-sustentáveis da cultura não indígena, que se adéquem às suas demandas e preceitos étnico-culturais. Observa-se ainda que as atuais preocupações e demandas dos povos indígenas necessitam, cada vez mais, de orientação e capacitação para construção, desenvolvimento e prestação de contas de tais projetos de fomento governamental ou de empresas privadas (envolvendo medidas compensatórias por impactos de projetos econômicos desenvolvidos em áreas indígenas ou no seu entorno). É nesse sentido que atuam as novas lideranças indígenas, principalmente dos professores indígenas, que participam tanto da elaboração como na gestão dos projetos, muitas vezes apoiados em outras instituições de apoio como as universidades ou organizações não governamentais.

Em Minas Gerais, este cenário se configura ainda por um processo de expropriação e etnocídio muito nítidos, associados, inclusive, a intervenções estatais e empresariais em terras indígenas de forma mais incisiva e regimental, por decretos e incisos governamentais, como discutiremos a seguir. 
SILVA, L. M. R.

Diáspora indígena no leste brasileiro: a resistência e o protagonismo dos povos indígenas nos "sertões" de Minas Gerais

\section{O Etnocídio indígena nas principais bacias hidrográficas de Minas Gerais}

Em Minas Gerais, havia inúmeras etnias que habitavam o território do estado até a segunda metade do século XVI, tendo algumas identificadas suas localizações, e outras, apenas descritas a partir de contatos estabelecidos em viagens. Tais relatos de diversos viajantes estrangeiros que estiveram no Brasil reforçam a enorme diversidade de grupos indígenas presentes em diferentes biomas (Cerrado, Mata Atlântica, etc.) do leste brasileiro. Além dos registros da fauna e flora, muitos naturalistas que vieram ao território brasileiro, inclusive nos séculos XVIII e XIX, se dedicaram e/ou se aprofundaram nas populações indígenas que encontravam nas áreas percorridas. Assim, são sobre estes relatos que existem atualmente referências, inclusive geográficas, dos povos indígenas que ocuparam, nos séculos passados, o estado de Minas Gerais, o qual foi intensamente estudado por diversos viajantes como Spix e Martius, Saint-Hilaire, dentre outros. A maioria dos grupos mencionados corresponde a índios do tronco lingüístico Macro-Jê, predominante nas regiões de Minas Gerais, Bahia e Espírito Santo, apesar de anteriormente esse território ter sido também ocupado por povos do Tronco Tupi, dos quais, na região do rio Doce, são encontrados ainda vestígios arqueológicos de cerâmicas, pinturas, etc.

Dentre os traços culturais dos Macro-Jê destaca-se o caráter nômade e a tendência ao desmembramento em pequenos grupos, o que justifica a presença de diversos subgrupos como já se ressaltou anteriormente. Prezia (2004) destaca que a formação dessa diversidade de subgrupos da etnia Borun (formados a partir de núcleos familiares não muito extensos) está relacionada à prática de associar o grupo à sua liderança (inclusive, etnomicamente) ou a uma característica geográfica que identificasse o seu território de caça. Cada subgrupo possuía suas especificidades lingüísticas e socioeconômicas, formando "numerosos bandos de coletores, caçadores e pescadores nômades, mas reconhecendo os limites de sua área de caça e coleta" (MATTOS, 1996, p.58). Segundo Ribeiro (1983), os Macro-Jê configuram os representantes indígenas mais genuinamente brasileiros, uma vez que só existiam (e ainda existem) dentro de nossas fronteiras. A autora destaca ainda que são povos de cultura material mais simples, embora apresentem organização social mais complexa e elaborada que a dos Tupi-guarani.

Tais populações destacam-se tanto pela influência na cultura mineira, como na própria toponímia de Minas Gerais, que conta com acidentes geográficos (córregos, serras, 
SILVA, L. M. R.

Diáspora indígena no leste brasileiro: a resistência e o protagonismo dos povos indígenas nos "sertões" de Minas Gerais

etc.), assentamentos humanos e a própria fauna e flora com nomes de origem indígena. Embora, Deus Et all (1998), destaquem que os grupos indígenas de Minas Gerais são majoritariamente do tronco lingüístico Macro-Jê, a principal contribuição da toponímia indígena nesse estado é basicamente de origem Tupi-guarani, idioma largamente difundido aqui através dos bandeirantes e jesuítas, por ser a língua mais comum no litoral e entre os "mestiços" que integravam o grupo dos bandeirantes. Os autores destacam ainda o caráter geográfico-ecológico da toponímia indígena, principalmente relacionada à hidrografia, como Córrego das Gamelas, Córrego Tamboril, Córrego Buriti, Córrego Jambreiro, Córrego da Aroeira, Córrego Catomumim, Córrego Samambaia e Córrego do Capão, todos fazendo referência à fauna ou à flora presente nesses lugares. Tal associação, segundo Gallais (2002), é construída a partir dos diversificados referenciais sócio-étnicos, mítico-afetivos e ecológicos, relacionados, inclusive, com a própria dinâmica de ocupação e deslocamento dessas populações ao longo dos principais cursos d'água de uma determinada região. Em Minas Gerais, essa incidência é verificada ao longo das bacias dos rios Doce e Jequitinhonha, como pôde ser observado no mapa de distribuição dos povos indígenas no período colonial (Figura 1).

A região do Vale do Rio Doce, no século XVIII, ainda mantinha-se como uma vasta área desconhecida pela geografia histórica da Capitania de Minas Gerais, uma vez que estrategicamente os "sertões do leste" compreendiam a faixa florestal contígua à região mineradora e configurava uma "barreira natural ao descaminho do ouro e que, portanto, deveria ficar impenetrável aos colonos" (AMANTINO, 2009, p.128). Os índios eram, nesse momento, os guardiões dessas fronteiras. No entanto, desde o século XVI já havia registros de bandeiras ou expedições militares na região, sendo muitas delas derrotadas por diversos grupos de botocudos (CEDEFES, 1987).

No início do século XIX, é que, com a redução da arrecadação do ouro na Colônia, se iniciaram as buscas de novos veios, e concomitantemente, o incremento da agricultura associada a núcleos populacionais do território mineiro ainda não agregados a uma atividade econômica significativa. Neste período o etnocídio dos povos indígenas se deu preponderantemente nas regiões de Minas Gerais, Mato Grosso e Goiás, decorrente da expansão econômica que provocou crescente pressão sobre as populações e territórios indígenas 
SILVA, L. M. R.

Diáspora indígena no leste brasileiro: a resistência e o protagonismo dos povos indígenas nos "sertões" de Minas Gerais

Figura 1: Mapa dos Povos Indígenas de Minas Gerais na 2a metade do século XVI - Período Colonial

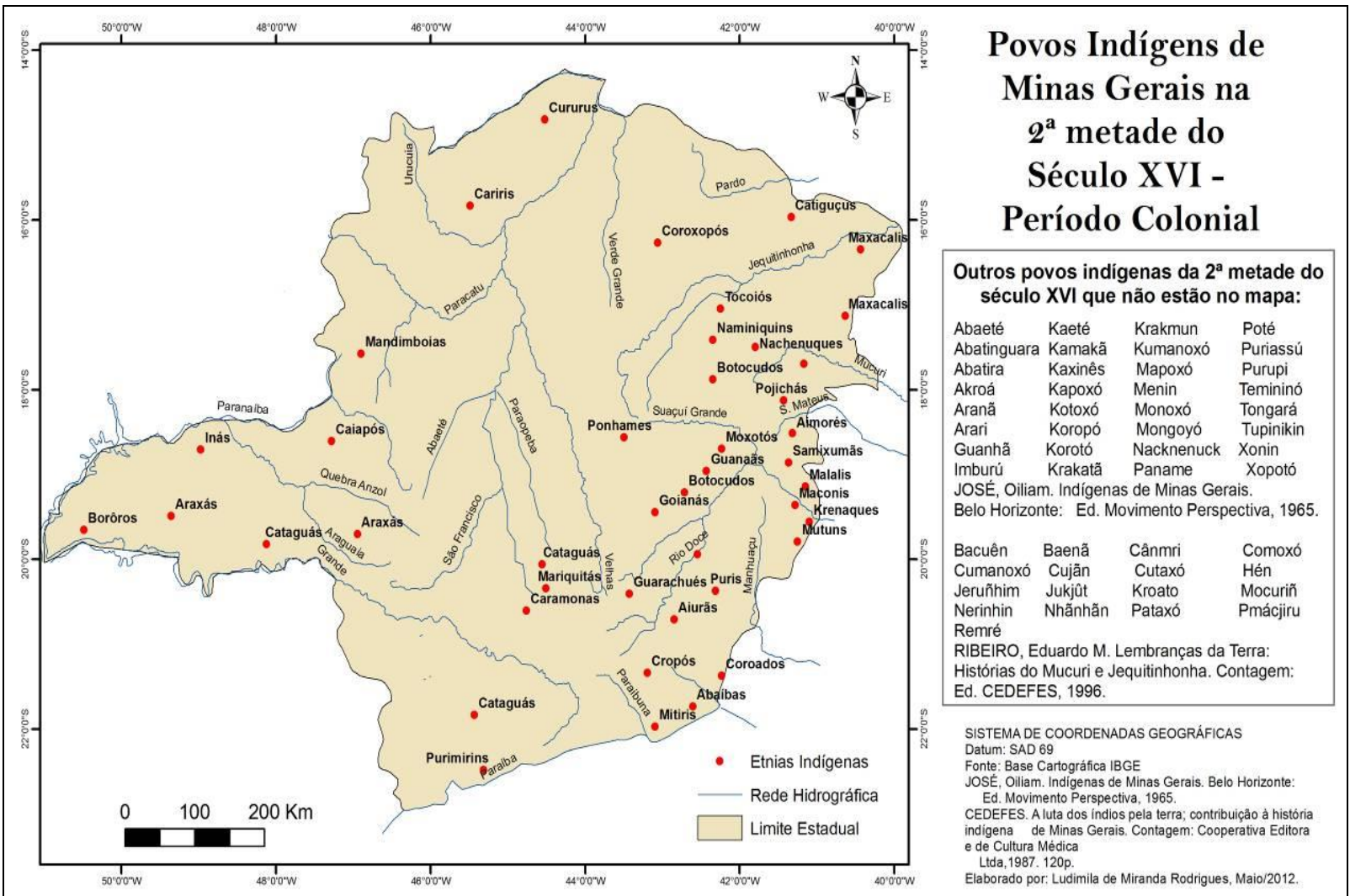

Fonte: elaborado pela autora.

Em Minas Gerais, devido aos ataques dos Botocudos e Puris às regiões já povoadas, os governadores da Capitania mantinham uma "guerra defensiva" através da instalação de presídios militares distribuídos estrategicamente. Nessa capitania, as entradas civilizadoras iniciaram-se, aliás, com a chegada de agricultores, com o objetivo de implantar na região o cultivo do algodão, fumo e café. Particularmente entre os rios Paraíba e Doce, foi atingido, assim, o território dos Puri-Coroado, que viviam na porção sul de Minas Gerais, norte do Rio de Janeiro, sudoeste do Espírito Santo e nordeste de São Paulo ocupando uma vasta área geográfica. Tanto os Botocudos, como os Puris tinham grande conhecimento desse território, conseguindo fugir ou obter sucesso em conflitos justamente devido a esse fator. Consequentemente, como estratégia de desmobilização das populações indígenas, os colonizadores começaram a levá-los para aldeamentos situados em outras regiões 
SILVA, L. M. R.

Diáspora indígena no leste brasileiro: a resistência e o protagonismo dos povos indígenas nos "sertões" de Minas Gerais

desconhecidas por eles, dificultando assim, sua fuga, pois desta forma, os índios perdiam seus referenciais geográficos e culturais (AMANTINO, 2009).

Os Botocudos, um dos povos indígenas mais numerosos do leste, dominavam um território cuja extensão "se estendia ao Norte e ao Nordeste de Minas Gerais até encontrar o Jequitinhonha. Pendia para o Leste, transpondo a Serra dos Aimorés e chegando às praias do Oceano Atlântico". Eles conviviam em seus territórios (que não eram totalmente ocupados devido à sua prática nômade) com outros grupos indígenas, com os quais vivenciavam conflitos; além dos inevitáveis confrontos com os portugueses (PESSOA, 2001, p.15).

No Jequitinhonha e Mucuri, destacavam-se tribos menores como os Maxakali, Malali, Pataxó, Panhame e Comoxó, além dos grandes grupos que compunham os "Botocudos" (Borun), como os Guerén, Endjerekmun, Kracmun, Amburé, Nack-Nenuck ou Aimoré. Com a implementação da Carta Régia de 1808, a expansão portuguesa sobre os territórios tradicionais desses povos, reduziu-se consideravelmente sua soberania territorial, o que desencadeou guerras indígenas contra os colonos (incentivados a guerrear e escravizar índios em troca de isenções fiscais) e intensificou os conflitos já existentes entre as aldeias. Em muitos casos, as tribos mais frágeis se uniam aos fazendeiros portugueses em busca de proteção contra os ataques dos grupos Borun (RIBEIRO, 1995).

A resistência Borun, como destaca Moreno (2011, p.122), consistia em "pequenos ataques guerrilheiros, emboscadas e armadilhas na mata" além das fugas para o interior das matas tropicais, das quais os brancos tinham muito medo. Ainda segundo o autor, a resistência indígena partiu dos grupos Nakreré, Gut Krak, Krenak, Krakmun, Pejaurun, Etwet, Naknenuk, Jiropok, Mijariam, Aranã, Potein e Krakatã, estando alguns ainda presentes no Vale do Rio Doce. Dentre as armadilhas de resistência, Moreno (2011, p.123) destaca as "armadilhas com espetos de bambu", que como espadas arrancavam a cabeça dos inimigos. Já Marcato (1979) destaca quatro atos principais de resistência desses grupos: a auto destruição individual e grupal com extinção ou negação da etnia; a recusa do contato com o homem branco, dando origem a frequentes movimentos de fuga; a não-violência e "integração" do grupo ao modo de vida do colonizador, a fim manter a sobrevivência do grupo e por fim a resistência armada.

O território tradicional da família Borun compreendia a porção sul e sudeste do atual estado da Bahia, leste e nordeste mineiros e noroeste e oeste do Espírito Santo. 
SILVA, L. M. R.

Diáspora indígena no leste brasileiro: a resistência e o protagonismo dos povos indígenas nos "sertões" de Minas Gerais

Originalmente existiam em torno de 14 grupos desta etnia conhecidos no território brasileiro, dentre eles: Gueren (com indicações de contato já em 1600, nas proximidades da costa do descobrimento - sul baiano); Etwét (1907); Pan-Pan, Bakué, Aranã, Poten, Nyepnyep,Convúg, Nakrehé (cuja localização nas bacias do Rio Doce e Jequitinhonha data de 1886); Takrukrak/Anket (1911); Poyicá (1912); Minyã-Yirugn (1938), e outros grupos sem datação de contato, como os Naknyanuk e Yiporok/Poyica. Nimuendajú indicou ainda que outros grupos chamados de Botocudos também foram contatados nos limiares de 1768, no alto curso da bacia do rio Itanhaém (IBGE, 1987).

Atualmente no Vale do Rio Doce vive um importante grupo de descendente dos Borun, o povo Krenak, que, por meio de sua resistência, se consolidaram enquanto uma identidade territorial formada através da contradição entre as estratégias-funcionais da cultura dominante (aldeamentos, presídios, agricultura) e da apropriação simbólico-expressiva, pelos indígenas, de suas paisagens culturais. Paisagens essas formadas pelas mais diversas vivências espaciais, oriundas dos processos de espoliação territorial, cultural e social, agregadas às estratégias de resistência construídas a partir de suas representações ideológicas, políticas e socioculturais capazes de conceber respostas aos desafios, por eles enfrentados de forma autônoma, e materializados por meio de recursos organizacionais próprios.

\section{A atual situação dos povos indígenas de Minas Gerais}

A redução de um território que abrangia porções de três unidades da Federação para uma área circunscrita ao interior de um município parece uma grande perda, embora, diante dos avassaladores processos de etnocídio e desterritorialização a que esses grupos foram submetidos, a manutenção, mesmo desse espaço exíguo, é uma grande conquista para os Krenak e demais grupos indígenas desse território, frente, inclusive, à realidade de algumas etnias que ainda se encontram abandonados nos grandes centros urbanos, ou cujas terras ainda não foram reconhecidas e/ou demarcadas.

Atualmente, existem doze etnias indígenas em Minas Gerais (Maxakali, Xakriabá, Krenak, Aranã, Mukurim, Pataxó, Pataxó Hã-hã-hãe, Katu-awá-arachá, Kaxixó, Puri, Xukuru-Kariri e Pankararu) distribuídas em 20 áreas, sendo 11 reconhecidas ou em processo de reconhecimento pela FUNAI, três em estudo (e que ainda não estão incluídas no 
SILVA, L. M. R.

Diáspora indígena no leste brasileiro: a resistência e o protagonismo dos povos indígenas nos "sertões" de Minas Gerais

mapeamento da FUNAI, mas já são discriminadas pelo ISA). E outras seis áreas ocupadas, e não regularizadas, que já são listadas pela ANAÍ, além dos índios desaldeados que domiciliaram seus núcleos populacionais dentro dos grandes centros urbanos, e cuja identificação e reconhecimento ainda estão em processo em consolidação.

Dos seis grupos, que atualmente encontram-se em terras ocupadas, dois são da etnia Pataxó (desagregados do grupo residente em Carmésia), que atualmente encontram-se no Parque Estadual do Rio Corrente, município de Açucena (com aproximadamente 60 indivíduos) e no Parque Estadual Serra da Candonga, município de Guanhães, (com aproximadamente 35 indivíduos). No Vale do Mucuri, município de Campanário, há um grupo de Pataxó-Hã-Hã-hãe oriundos da terra Caramuru/Paraguassu na Bahia. Os Puri (que ocupam atualmente o Parque Estadual da Serra do Brigadeiro - Araponga) e os Katu-awáarachás (localizados no município de Araxá) são grupos de emergência étnica muito recente (ANAÍ, 2010). Vale ressaltar que, Segundo Deus (2012, p.45), a situação particular desses grupos emergentes, ou "ressurgidos", é, aliás, fruto de um "processo de resgate da identidade" indígena, por meio da retomada de culturas adormecidas, que hoje despertam, e se assumem como "indígenas remanescentes", "reterritorializando-se" através de um emergente processo de auto-reconhecimento e de luta por seus direitos.

Destacamos ainda que parte desses territórios já se encontra regularizada (homologados e registrados) pelo Instituto Nacional de Colonização e Reforma Agrária (INCRA), mas a maioria encontra-se em pleito para regularização. Outras, apesar de, até o momento, estarem aguardando regularização e/ou estudos, já foram demarcadas, como a dos Maxakali de Teófilo Otoni e Ladainha. Desse modo, algumas comunidades indígenas de Minas Gerais, além de terem tido usurpadas muitas de suas tradições, não garantiram ainda nenhum território de direito, como definido no art. 231, $\S \S 2^{\circ}, 3^{\circ}$ e $7^{\circ}$ da Constituição Federal (BRASIL, 1988).

Vale ressaltar também a presença no Estado de grupos desaldeados ${ }^{4}$, das etnias Pataxó, Pataxó Ha-Ha-Hãe, Aranã e Xakriabá. Algumas, inclusive, se organizam em associações, como a do grupo étnico Aranã chamada: Associação Indígena Pedro Sangê (AIPS); e outra, dos Pataxó Hã Hã Hãe, denominada Associação dos Povos Indígenas de

\footnotetext{
${ }^{4}$ Índios residentes fora das aldeias.
} 
SILVA, L. M. R.

Diáspora indígena no leste brasileiro: a resistência e o protagonismo dos povos indígenas nos "sertões" de Minas Gerais

Belo Horizonte e Região Metropolitana (APIBHRM), através das quais eles apresentam com maior autonomia, suas demandas sociais, políticas, econômicas e culturais. Sabe-se também de grupos de indígenas que residem em outras cidades mineiras, como Governador Valadares, Montes Claros, Pirapora, Pompeu, Martinho Campos e Pará de Minas, dentre outras. Contudo, como destaca Lima (2011) a presença desses grupos no espaço urbano os "desautoriza", e os descaracteriza como tais em termos judiciais, destituindo-os dos direitos diferenciados garantidos pela Constituição (que não se remete, em momento algum, à categoria de índios “desaldeados").

Seguindo a tendência da década de 1980 de mobilização e organização política, os índios do Leste criaram a "Articulação dos Povos Indígenas do Nordeste, Minas e Espírito Santo" (APOINME) - entidade que além de articular povos de diferentes etnias e estados, busca realizar a sua representação junto aos órgãos federais, participando de discussões, assembleias e chamadas de projetos para a melhoria de expectativa e qualidade de vida nas aldeias.

Minas Gerais possui a extensão territorial de 82.524 ha de terras indígenas para aproximadamente 9.489 índios aldeados, cujos territórios variam de 78 a 46.415 hectares. Muitos deles atualmente já se encontram homologados, e passaram ou estão passando por processo de revisão de suas fronteiras, como o do povo Krenak, cuja demanda pela incorporação do Parque Estadual de Sete Salões ao território tribal encontra-se em estudo pela FUNAI de Governador Valadares.

Uma situação ainda muito frequente entre os índios de Minas Gerais é a precariedade da saúde. Na TI Maxakali há denúncias do Ministério Público de abandono de assistência pela FUNASA, com a ocorrência, nas comunidades, de surtos frequentes de gastroenterite, diarreia, além de desnutrição, contaminação bacteriana da principal fonte de água na aldeia (o rio Umburama), falta de higiene, ausência de coleta de lixo, dentre outros fatores que fragilizam a situação dessa e tantas outras aldeias indígenas em Minas Gerais.

Apesar da ausência de informações demográficas em algumas terras indígenas nos anos anteriores, observou-se a tendência de aumento populacional principalmente na virada dos anos 1990 para 2000, e a sua manutenção/ incremento menos expressivo nos últimos anos. Contudo, o fenômeno que mais se destaca é o surgimento de novas áreas e grupos emergentes. Processo esse conhecido como etnogênese indígena, configurado a partir de 
SILVA, L. M. R.

Diáspora indígena no leste brasileiro: a resistência e o protagonismo dos povos indígenas nos "sertões" de Minas Gerais

"mecanismos sociais que permitem um determinado grupo social estabelecer e construir uma autoconsciência e uma identidade coletiva contra uma ação de desrespeito com vistas ao reconhecimento e à conquista de objetivos coletivos" (ISA, 2013a, p.11). Esse novo fenômeno, que muitos consideram como uma “(re)invenção cultural”, parte, no entanto, de um movimento de reafirmação da identidade indígena que proporciona aos grupos ressurgidos condições para a construção de um sentimento de unidade, pertencimento e destino comum.

Os indígenas, além de buscarem seus direitos constitucionais, encontram-se assim cada vez mais mobilizados e articulados no intuito de resgatar e preservar sua cultura através do desenvolvimento de projetos socioambientais nas aldeias. Segundo IS A (2013), no período de 2009 a 2011 foram iniciados oito projetos com participação indígena em Minas Gerais, sendo três com enfoque no "Ambiente" (e cujo conteúdo direciona-se à interação sociocultural com o ambiente, através do resgate das práticas de manejo tradicional e sustentável para subsistência dos Maxacali); quatro de "infraestrutura" (para a construção de casas de farinha, casas de plantas medicinais e engenho comunitário de rapadura nos territórios Xacriabá, no norte de Minas) e por fim um de enfoque "Cultural", vinculado ao resgate da história e língua do povo Kaxixó.

O movimento de reafirmação desses povos, segundo Dias Junior; et al. (2008), demograficamente se expressa no incremento populacional indígena no estado, que em 2000, situou-se em torno de 10,8 \%, enquanto que a população brasileira, em geral, apresentou um crescimento de apenas 1,6\%. Tais índices, frente à impossibilidade de representarem apenas um brusco aumento da fecundidade e queda da mortalidade, levaram os pesquisadores a inferirem sobre a possibilidade de aumento da migração e da autodeclaração indígena. Pois, enquanto em 1991, o IBGE amostrava 6.118 indígenas em Minas Gerais; em 2000, verificouse uma elevação desse contingente para 48.720 pessoas, registrando-se um aumento de 42.602 indivíduos na população total de indígenas no estado, o que poderia ser explicado tanto pelo crescimento vegetativo (3\%), como pela migração $(2,7 \%)$ e autodeclaração $(94,3 \%)$. Outro dado interessante é o aumento das autodeclarações no espaço urbano, o que evidencia, ainda, um processo de reclassificação racial no período de 1991 à 2000, ligado, acredita-se, à mudança do sentido e percepção da condição de "ser índio".

Quando nos deparamos com o histórico do genocídio das populações indígenas no Leste Brasileiro e das práticas de extermínio realizadas por diversos segmentos sociais e 
SILVA, L. M. R.

Diáspora indígena no leste brasileiro: a resistência e o protagonismo dos povos indígenas nos "sertões" de Minas Gerais

organismos governamentais, nos surpreendemos com a sabedoria e resistência desses povos. E vale ressaltar que, esses resultados atuais de crescimento populacional e conquistas políticas, sociais e territoriais advêm de muito sofrimento, perdas e histórias que nunca mais serão esquecidas no imaginário indígena, como destacam diversas dessas etnias.

\section{CONSIDERAÇÕES FINAIS}

Dialogar sobre o passado, presente e futuro desses povos faz-se cada vez mais necessário no contexto atual, uma vez que, muitos de seus direitos adquiridos nos últimos anos vêm sendo ameaçados por uma série de políticas públicas e posicionamentos estigmatizantes e desconstrutivos da luta e resistência indígena. A análise das dinâmicas espaciais e sociais desses povos no leste brasileiro tem por objetivo a compreensão das formas visíveis e invisíveis dos discursos sociais dos grupos humanos, que atribuem ao seu espaço vivido um sistema de signos e significações construído a partir de relações culturais, sociais, políticas e econômicas. Posto isso, o desafio do olhar geográfico frente aos processos sociais, sob o viés cultural, remete-se a essa busca pela compreensão das interpretações/percepções simbólicas que se configuram sobre a vida coletiva.

Nesse sentido os povos indígenas do leste brasileiro, além de transmitirem a essência cultural e social vinculada à sua tradicionalidade étnica, precisam ainda transmitir entre suas gerações os relatos e histórias de vida que remetem a esses processos de etnocídio indígena, que os fez chegar às condições atuais como forma de manutenção da identidade cultural e da própria resistência indígena. Nessa perspectiva a cultura representa não apenas a herança e a experiência de um povo, mas uma projeção em direção ao futuro, apresentando-se ainda como um documento aberto a múltiplas leituras. Eis então mais um desafio do olhar do geógrafo em procurar captar as diversas leituras de uma paisagem, combinando de forma efetiva todos esses olhares.

Todavia, mesmo reconhecendo a injustiça de todos esses processos destacados ao longo deste artigo, muitas pessoas ainda quando veem as reações desses grupos às agressões, espoliações e processos de etnocídio vivenciados por mais de 500 anos, direcionam aos povos indígenas ações e discursos preconceituosos que desconsideram seus direitos previstos pela Constituição; e muitas vezes invalidados, inclusive, pelo próprio Estado, que 
SILVA, L. M. R.

Diáspora indígena no leste brasileiro: a resistência e o protagonismo dos povos indígenas nos "sertões" de Minas Gerais

inconstitucionalmente, permitiu e ainda permite a remoção e o desrespeito a suas terras tradicionais.

E, infelizmente, é essa concepção acrítica sobre a cultura indígena que predomina na percepção dessas sociedades, que, mesmo frente a tantos processos de extermínio, ainda resistem em pequenas áreas remanescentes de seu território tradicional (realidade concernente, sobretudo, às comunidades indígenas domiciliadas fora da Amazônia, hoje em dia). São essas identidades de resistência construídas por esses grupos ainda hoje marginalizados, que fortalece a luta desses povos, que estão cada vez mais voltados a uma nova maneira de conceber o mundo, emergindo por meio de uma politização de suas práticas e comportamentos sociais, com a construção de uma consciência de fortalecimento e ressignificação das identidades, agregando às suas tradições e memórias, projetos alternativos de produção e organização sociocultural, bem como de afirmação e participação política.

\section{AGRADECIMENTOS}

À Coordenação de Aperfeiçoamento de Pessoal de Nível Superior (CAPES) pela concessão de bolsa de estudos.

\section{REFERÊNCIAS}

AMANTINO, Márcia. Entre o genocídio e a escravidão. Revista do Arquivo Público Mineiro. Belo Horizonte, vol. 45, fasc. 2, 120-135, jul/dez/2009. Disponível em: < http://www.siaapm.cultura.mg.gov.br/acervo/rapm_pdf/Ensaio2009-2.pdf >. Acesso em 30/04/2013.

ASSOCIAÇÃO NACIONAL DE AÇÃO INDÍGENA - ANAÍ. Povos Indígenas, 2010. Apresenta o histórico e a situação fundiária das terras indígenas por estado brasileiro. Disponível em:< http://www.anai.org.br/povos.asp>. Acesso em: 06/07/2012.

BRASIL. Constituição (1988). Constituição da República Federativa do Brasil, 1988. Brasília: Senado Federal, Centro Gráfico, 1988. 292p.

CENTRO DE DOCUMENTAÇÃO ELOY FERREIRA DA SILVA - CEDEFES. A luta dos índios pela terra; contribuição à história indígena de Minas Gerais. Contagem: Cooperativa Editora e de Cultura Médica Ltda, 1987. 120p.

DEUS, José Antônio Souza de; FANTINEL, Lúcia Maria; NOGUEIRA, Marly. Índios e Quilombos nas Regiões de Antiga Mineração do Brasil: A Dimensão Geohistórica e a Percepção do Estado. Caderno de Filosofia e Ciências Humanas. Ano VI, nº 11, out/1998. 
SILVA, L. M. R.

Diáspora indígena no leste brasileiro: a resistência e o protagonismo dos povos indígenas nos "sertões" de Minas Gerais

DEUS, José Antônio Souza de. Paisagens culturais alternativas e protagonismo etnopolítico de comunidades tradicionais no hiterland brasileiro. In: TUBALDINI, Maria Aparecida S.; GIANASI, Lussandra Martins (org.). Agricultura Familiar, cultura camponesa e novas territorialidades no Vale do Jequitinhonha: gênero, biodiversidade, patrimônio rural, artesanato e agroecologia. Belo Horizonte: Fino Traço, 2012. p.35-50.

GALLAIS, Jean. Alguns aspectos do espaço vivido nas civilizações do mundo tropical. In: CORRÊA, Roberto Lobato; ROSENDAHL, Zeny (Orgs). Geografia Cultural: um século (3). Rio de Janeiro: EdUERJ, 2002. p.63-82.

INSTITUO BRASILEIRO DE GEOGRAFIA E ESTATÍSTICA - IBGE. Mapa etnohistórico de Curt Nimuendaju. Rio de Janeiro: IBGE, $2^{a}$ impressão, 1987. 94p.: mapa.

INSTITUTO SOCIOAMBIENTAL - ISA. Povos Indígenas no Brasil Atual, 2013. Histórico sobre os povos indígenas na atualidade. Disponível em:<

http://pib.socioambiental.org/pt/c/no-brasil-atual/quem-sao/povos-indigenas $>$. Acesso em: $12 / 03 / 2011$.

De Olho nas Terras Indígenas no Brasil, 2013a. Banco de dados sobre a atual situação dos povos indígenas no Brasil. Disponível em: $<$ http://ti.socioambiental.org/ptbr/\#!/pt-br/terras-indigenas>. Acesso em 08/05/2013.

LIMA, Ana Paula Ferreira. Direitos iguais, (pre)conceitos diferenciados. 2011. Disponível em: $\langle$ http://www.cedefes.org.br/index.php? $\mathrm{p}=$ colunistas_detalhe\&id_pro=9 > Acesso em: 27 de maio de 2011.

MARCATO, Sônia de Almeida. A Repressão contra os botocudos em Minas Gerais. Boletim do Museu do Índio: Etno-história. Rio de Janeiro: Fundação Nacional do Índio, n.1, p.3-59, maio. 1979.

MATTOS, Isabel Missagia. Borum, Bugre, Kraí: a constituição social da identidade e memória étnica krenak. 1996. 221f. Dissertação (Mestrado em Sociologia) - Faculdade de Filosofia e Ciências Humanas, Universidade Federal da Minas Gerais, Belo Horizonte, 1996.

MELATTI, Julio Cezar. Áreas Etnográficas da América Indígena. Brasília: Instituto de Ciências Sociais - Departamento de Antropologia, 2009. (Capítulo 31 - Leste). 9p. Disponível em: <http://www.juliomelatti.pro.br/areas/31leste.pdf>. Acesso em: 26/05/2011.

MORENO, Cézar. A colonização e o Povoamento do Baixo Jequitinhonha no século XIX: A guerra contra os índios. $2^{\mathrm{a}}$ Ed. Belo Horizonte: Canoa das Letras, 2011. 192p. (Coleção Testemunho Jequitinhonha; 4).

PESSOA, Hélio dos Santos. O negociador de vidas na saga do Rio Doce. Belo Horizonte: Ed. Plurarts, 2001. (Vol. II - As Lutas). 297p. 
SILVA, L. M. R.

Diáspora indígena no leste brasileiro: a resistência e o protagonismo dos povos indígenas nos "sertões" de Minas Gerais

PREZIA, Benedito. Indígenas do Leste do Brasil: destruição e resistência: subsídios didáticos para o ensino fundamental e médio. São Paulo: Paulinas, 2004. (Coleção Ameríndia, 2). $118 \mathrm{p}$.

RIBEIRO, Berta Gleizer. O índio na história do Brasil. São Paulo: Ed. Global, 1983. 128p.

RIBEIRO, Eduardo Magalhães (Org.). Lembranças da terra: histórias do Mucuri e Jequitinhonha. Contagem: CEDEFES; SEGRAC, 1995. 235 p.

SAMPAIO, José Augusto Laranjeiras. Breve história da presença indígena no extremo sul baiano e a questão do território pataxó do Monte Pascoal. Cadernos de História, Belo Horizonte, v.5, n.6, p.31-46, jul.2000. Disponível em:< http://periodicos.pucminas.br/index.php/cadernoshistoria/article/view/1703/1829>. Acesso em: 14/05/2013.

História e Presença dos Povos Indígenas na Bahia. Associação Nacional de Ação Indigenista, 2010. 8p. Disponível em: <http://www.anai.org.br/povos_ba.asp>. Acesso em: 08/05/2013.

\section{Autora}

Ludimila de Miranda Rodrigues Silva - Possui Graduação e Mestrado em Geografia, ambos cursados pela Universidade Federal de Minas Gerais (UFMG). Atualmente é Doutoranda pelo Programa de Pós-Graduação em Geografia da Universidade Federal de Minas Gerais (UFMG).

Artigo recebido em: 17 de janeiro de 2018.

Artigo aceito em: 30 de junho de 2018.

Artigo publicado em: 30 de junho de 2018. 